\title{
Hemodynamic index of animals with burning injury treated with "Acerbin"
}

\author{
Alexander Pereverzev*, Elena Everstova, and Vladimir Tolkachev
}

Kursk State Agricultural Academy named after I. I. Ivanov, 70 Karl Marks Street, Kursk, 305021, Russia,

\begin{abstract}
Thermal injuries are wide spread among home pets and are represented as a recent problem of veterinary medicine because of the lack of anti-burn drugs adapted for use in veterinary medicine. In this regard, the aim of our work is to certify the vulnerary spray "Acerbin" for medical purposes in the treatment of thermal injuries of animals and to evaluate its therapeutic potency according to the dynamics of healing burn injuries and recovery of the blood cell composition. The research was carried out on 60 laboratory white mice. Thermal injuries of the skin integument on the dorsal surface of the croup were simulated; the "Acerbin" spray was further applied. To achieve the aim, the blood samples and planimetric measured tests of the area of burn defects were taken on the 3rd, 5th, 7th, 10th and 14th day of treatment. The samples were analyzed by the quantitative content of erythrocytes, thrombocytes, leucocytes and $\mathrm{cHb}$ (blood hemoglobin concentration) using an automatic hematological analyzer "Abacus vet 10". Planimetric indicators of the area of burns were subjected to mathematical processing with the calculation of the rate of epithelization of the burn injury. The obtained hematological and planimetric digital indicators were processed by statistical methods of analysis, compared and then interpreted.
\end{abstract}

\section{Introduction}

Thermal injury is the skin integument and deep-lying tissues damage, appeared as a result of high temperatures exposure [1]. More than 600000 burns of animals are registered every year in Russia, representing from 50 to $60 \%$ of all diagnosed therapeutic injuries [2]. According to the data published in The British Small Animal Veterinary Association, thermal injuries amount to about $20 \%$ of all recorded surgical pathologies of animals. Thermal burns, in addition to local pathological changes, cause deep hemostasis disorders and are difficult to treat. That is why the problem of thermal injuries treatment is one of the most actual issues for veterinary science and practice. The world pharmaceutical market offers a wide choice of drugs, but most of them are not adapted to veterinary usage. This fact complicates the medical activities of vets faced with the problem of the necessity of burning injury treatment for animals [3]. In this regard, the development of new anti-burn veterinary drugs that can effectively reduce the healing time of burn defects is necessary. Such drugs can also normalize hemodynamic parameters that significantly affect the relief of polymorphic pathology of burn injury animals [4]. That is why the aim of our work is to certify the vulnerary spray "Acerbin" for medical purposes in the treatment of thermal injuries of animals and to evaluate its therapeutic potency according to the dynamics of healing of burn injuries [5].

\section{Materials and methods}

Scientific research was carried out at the Surgery and Therapy Department of the FEBEI of HE "Kursk State Agricultural Academy named after I. I. Ivanov". To achieve the aim, thermal injuries were simulated on 60 laboratory white mice, subjected to deep sedation. That was made in accordance with the "European Convention for the Protection of Vertebrates Used for Experiments or Other Scientific Purposes".

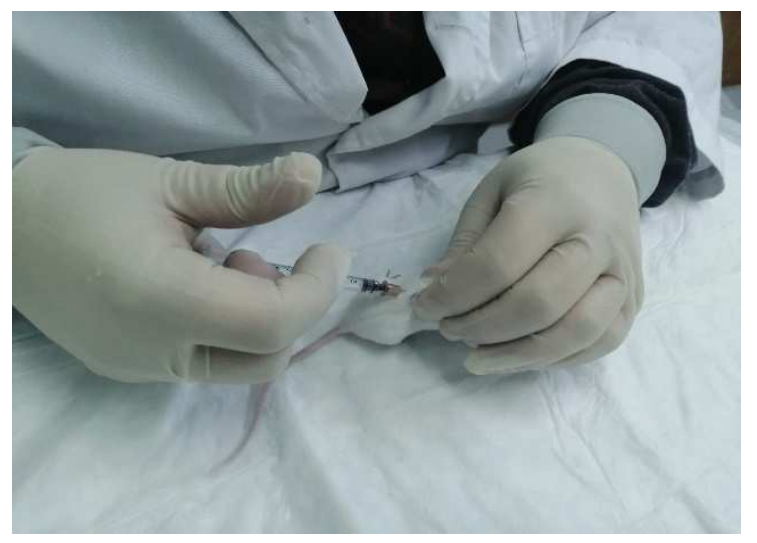

Fig. 1. Deep sedation of animals.

Further, an operating field was prepared with the dorsal surface of the croup in accordance with the asepsis and antiseptics rules. The coat was cut, shaved,

\footnotetext{
* Corresponding author: pereverzeff.sasha@yandex.ru
} 
treated with a swab soaked in a 5\% alcohol iodine solution. After the preparation, the working part tip of the hot electric soldering iron was applied to the skin with an exposure of 5 seconds.

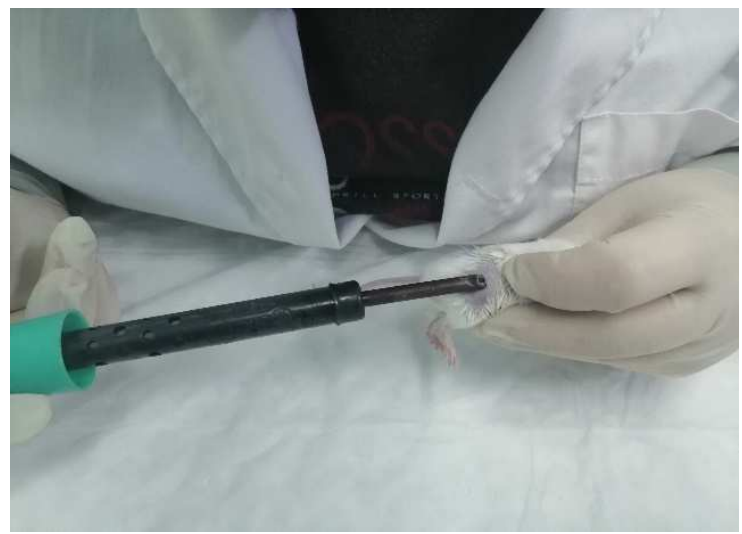

Fig. 2. Third degree thermal burns of the skin were simulated.

Thus, the third degree thermal burns of the skin were simulated. Laboratory animals with simulated skin burns were brought out of the state of deep sedation and further treated with applications of the vulnerary spray "Acerbin" on the 3rd, 5th, 7th, 10th and 14th days. During the experiment, blood samples were taken for general clinical analysis on an automatic hematology analyzer "Abacus vet 10" before treatment. Planimetric measurements of the burn defects area were also performed on the $3 \mathrm{rd}$, 5th, 7th, 10th and 14th days. Planimetric research included transferring burn contours to millimeter paper, counting whole squares within the contour boundaries. Thus, obtaining the area of thermal burns at the time of measurement was accomplished. The obtained digital indicators were subjected to mathematical processing to calculate the rate of epithelization of burn injury $\Delta S(1)$ :

$$
\Delta \mathrm{S}=\frac{(S-S n) * 100}{\mathrm{~S} * \mathrm{t}}
$$

where $\mathrm{S}$ is the size of the wound area at the previous measurement; $\mathrm{Sn}$ is the size of the wound area at the present moment; $t$ is the number of days between the first and subsequent measurements. Hematological research included the counting of quantitative content of erythrocytes, thrombocytes, leucocytes and blood hemoglobin concentration at the appropriate time of treatment.

Further, all the digital indicators were subjected to statistical processing to determine the degree of reliability, for comparative assessment and interpretation. The conclusion on the influence of the treatment of animals with burn injury using the vulnerary spray "Acerbin" on the rate of healing of burns and normalization of general hemodynamics was formulated on this basis.

\section{Results and discussion}

The results of the research showed that the area of simulated thermal injuries was $42.30 \pm 3.20 \mathrm{~mm}^{2}(\mathrm{p} \leq 0.05)$. And the quantitative content of erythrocytes, thrombocytes, leucocytes and $\mathrm{cHb}$ (blood hemoglobin concentration) in the vascular bed of the burn injured animals contained $8.80 \pm 0.44 \mathrm{G} / \mathrm{mcl} \quad(\mathrm{p} \leq 0.05)$, $471.60 \pm 27.25 \mathrm{~T} / \mathrm{mcl} \quad(\mathrm{p} \leq 0.05)$ and $4.80 \pm 0.28 \mathrm{~T} / \mathrm{mcl}$ $(\mathrm{p} \leq 0.05)$ and $153.00 \pm 2.58 \mathrm{~g} / \mathrm{l}(\mathrm{p} \leq 0.05)$, respectively.

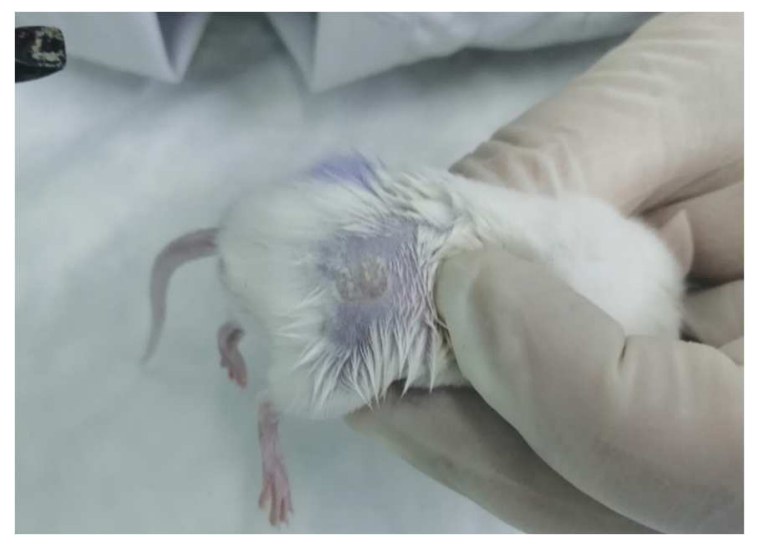

Fig. 3. Burn injury before treatment.

On the $3^{\text {rd }}$ day of the treatment with the "Acerbin" spray, the burnt area was $31 . \pm 2.72 \mathrm{~mm}^{2}(\mathrm{p} \leq 0.05)$. It means that it decreased compared to the initial results by $8.35 \pm 2.12 \mathrm{~mm}^{2}(\mathrm{p} \leq 0.05)$ or by $26.24 \%(\mathrm{p} \leq 0.05)$. At the same time, there was a decrease of the quantitative content of erythrocytes by $31.91 \%(\mathrm{p} \leq 0.05)$. It can be compared to the values of $6.08 \pm 0.21 \mathrm{G} / \mathrm{mcl}(\mathrm{p} \leq 0.05)$, thrombocytes - by $37.58 \% \quad(297.00 \pm 26.48 \quad \mathrm{~T} / \mathrm{mcl})$ $(\mathrm{p} \leq 0.05)$ and a sharp increase of the leucocytes quantitative content by $53.11 \% \quad(7.38 \pm 1.20 \mathrm{~T} / \mathrm{mcl})$ $(\mathrm{p} \leq 0.05)$ relative to pre-therapeutic indicators in a sign of burnt area reduction by the 3rd day.

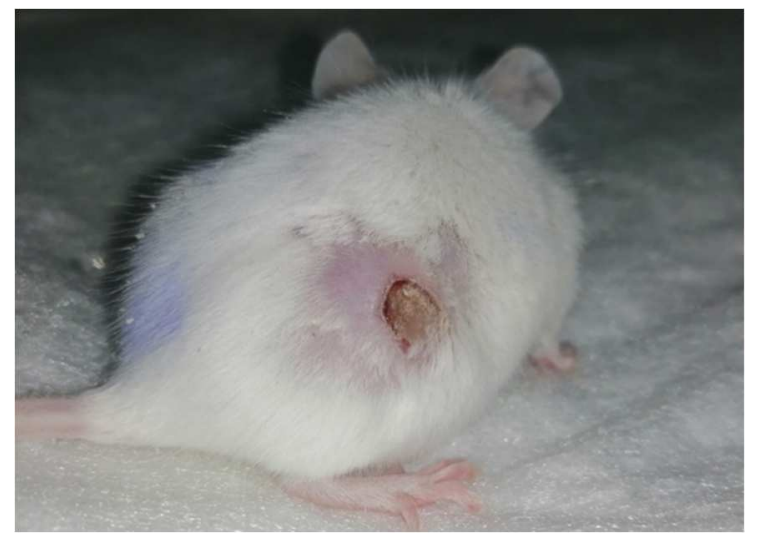

Fig. 4. Burn on the 3rd day of the treatment with the "Acerbin" spray.

On the $5^{\text {th }}$ day of treatment the burnt area additionally decreased by $8.54 \pm 0.87 \mathrm{~mm}^{2}(\mathrm{p} \leq 0.05)$ or by $43.09 \%$ $(\mathrm{p} \leq 0.05)$ and the burns size was equal to $17.50 \pm 1.70 \mathrm{~mm}^{2}$ $(\mathrm{p} \leq 0.05)$. At the same time, there was a further decrease of the quantitative content of erythrocytes in the vascular bed by $11.35 \%(p \leq 0.05)$ to $5.39 \pm 0.14 \mathrm{G} / \mathrm{mcl} \quad(p \leq 0.05)$. Following the decrease in the erythrocytes population, the quantitative content of hemoglobin decreased to $77.20 \pm 1.14 \mathrm{~g} / \mathrm{mcl}(\mathrm{p} \leq 0.05)$, and was less than that on the 3rd day by $8.53 \%(\mathrm{p} \leq 0.05)$, and before treatment - by $49.34 \%(p \leq 0.05)$. Further hematological research on the 
5th day of the experiment showed the decrease of the quantitative content of leucocytes by $19.24 \%(5.96 \pm 0.36$ $\mathrm{T} / \mathrm{mcl})(\mathrm{p} \leq 0.05)$ and the increase of the thrombocytes level by $6.40 \%(316.00 \pm 21.01 \mathrm{~T} / \mathrm{mcl})(\mathrm{p} \leq 0.05)$, relative to the results of the general clinical blood test on the 3rd day of the experiment. Thus, on the 5th day of treatment of burns with the vulnerary spray "Acerbin", the cellular composition of the blood differed from the pretherapeutic parameters by the reduction of the quantitative content of erythrocytes and thrombocytes by $38.86 \%(\mathrm{p} \leq 0.05)$ and $32.90 \%(\mathrm{p} \leq 0.05)$, as well as the increase of the leucocytes population by $24.16 \%$ $(\mathrm{p} \leq 0.05)$.

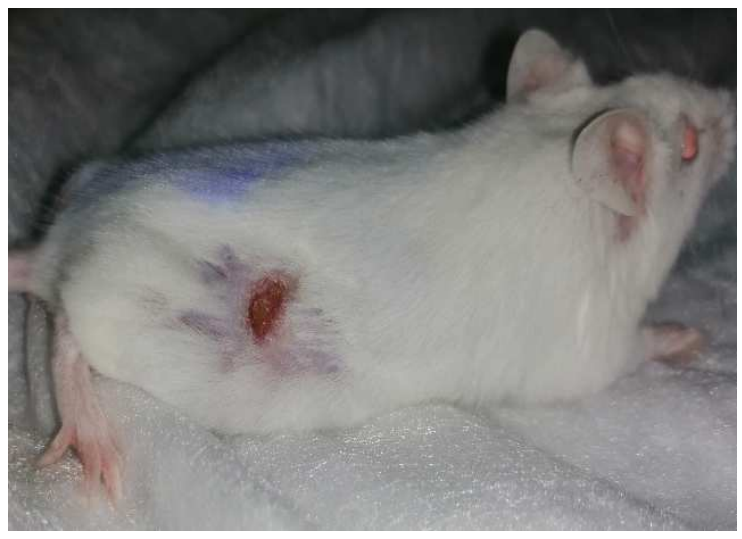

Fig. 5. Burn on the 5th day of the treatment with the "Acerbin" spray.

After a week of treatment with "Acerbin" burns areas reduced to $10.60 \pm 0.73 \mathrm{~mm}^{2}(\mathrm{p} \leq 0.05)$. It means that the area of burns was less by $6.61 \pm 0.24 \mathrm{~mm}^{2}(\mathrm{p} \leq 0.05)$ or by $39.43 \%(p \leq 0.05)$ than on the 5 th day of therapy. The hemodynamics of the burn injured animals on the 7 th day of therapy showed that the content of erythrocytes and leucocytes continued to decrease by $19.57 \%(\mathrm{p} \leq 0.05)$ and $17.78 \%(\mathrm{p} \leq 0.05)$ to the values of $4.89 \pm 0.08 \mathrm{G} / \mathrm{mcl}$ $(\mathrm{p} \leq 0.05)$ and $4.90 \pm 0.17 \mathrm{~T} / \mathrm{mcl}(\mathrm{p} \leq 0.05)$. And the content of thrombocytes and the blood hemoglobin concentration increased by $5.88 \%(334.60 \pm 26.34 \mathrm{~T} / \mathrm{mcl})(\mathrm{p} \leq 0.05)$ and by $21.76 \%(94.00 \pm 1.10 \mathrm{~g} / \mathrm{l})(\mathrm{p} \leq 0.05)$ in comparison with the results of hematological studies on the 5th day of the experiment. Besides, the $7^{\text {th }}$ day of the research showed that the quantitative content of erythrocytes was less than that on the 3rd day and before the start of treatment by $19.57 \% \quad(p \leq 0.05)$ and $45.24 \% \quad(p \leq 0.05)$, respectively. Despite this fact, the reverse dynamics of the hemoglobin level was observed. Its concentration increased by $11.37 \%$ ( $\mathrm{p} \leq 0.05)$, compared to the results on the 3rd day of treatment, but it was less than that at the beginning of the experiment by $38.32 \%(\mathrm{p} \leq 0.05)$. At the same time, the level of thrombocytes was higher than that on the 3rd day by $12.66 \%(\mathrm{p} \leq 0.05)$, but less than it was before therapy by $29.68 \%(\mathrm{p} \leq 0.05)$. The analysis of the registered leukocytosis showed that the quantitative content of leucocytes on the 7th day was less than on the 3rd one by $33.60 \%(\mathrm{p} \leq 0.05)$, but slightly exceeded the pre-therapeutic index by $2.08 \%(\mathrm{p} \leq 0.05)$.

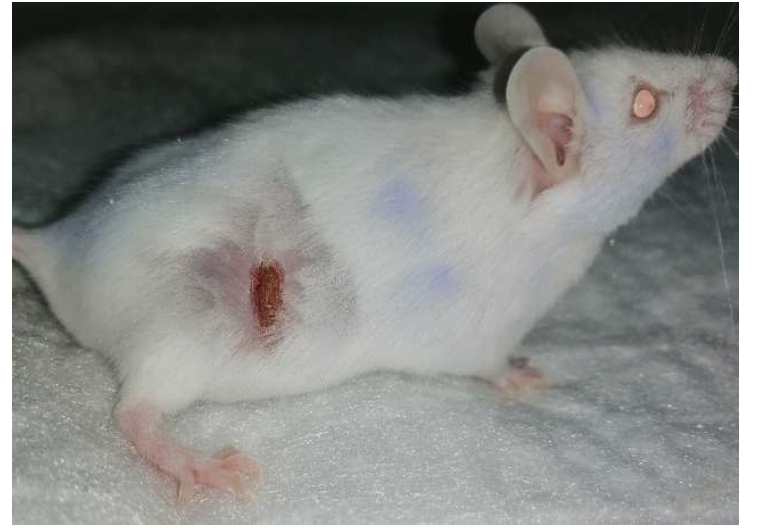

Fig. 6. Burn on the 7th day of the treatment with the "Acerbin" spray.

The area of thermal burns on the $10^{\text {th }}$ day of treatment was $5.40 \pm 0.67 \mathrm{~mm}^{2}(\mathrm{p} \leq 0.05)$ and it was less than that on the 7 th day of treatment by $4.98 \pm 0.44 \mathrm{~mm}^{2}$ $(p \leq 0.05)$ or by $49.05 \%(p \leq 0.05)$. At the same time, the quantitative content of erythrocytes and thrombocyte in the blood was less than that on the 7th day of the research by $5.72 \%(\mathrm{p} \leq 0.05)$ and $10.61 \%(\mathrm{p} \leq 0.05)$, and the content of thrombocytes was more by $13.21 \%(\mathrm{p} \leq 0.05)$. The blood hemoglobin concentration increased up to $30.21 \%(\mathrm{p} \leq 0.05)$. It was higher than that on the 7 th day of the experiment. Thus, there were the following hemodynamic indexes in the vascular bed of the burninjured patients. Erythrocytes were $4.61 \pm 0.14 \mathrm{G} / \mathrm{mcl}$ $(\mathrm{p} \leq 0.05)$, leucocytes $-4.38 \pm 0.16 \mathrm{~T} / \mathrm{mcl} \quad(\mathrm{p} \leq 0.05)$, thrombocytes - 378.80 $\pm 18.59 \mathrm{~T} / \mathrm{mcl} \quad(\mathrm{p} \leq 0.05)$, and hemoglobin $-122.40 \pm 1.09 \mathrm{~g} / \mathrm{l}(\mathrm{p} \leq 0.05)$. Evaluating the hemodynamics of the patients, it was found that, the number of erythrocytes in the blood of the laboratory animals treated with the vulnerary spray "Acerbin" by the 10th day of the experiment was less than that on the 3 rd day of treatment. It was less by $24.18 \%(p \leq 0.05)$ than that on the 5th day of treatment - by $14.77 \%(\mathrm{p} \leq 0.05)$, than that before treatment - by $48.38 \%(\mathrm{p} \leq 0.05)$. The similar dynamics was recorded in the relation to the total number of leucocytes, so by the 10th day the total number of leucocytes was less than that before treatment; on the 3rd and 5th days of the experiment by $40.68 \%(\mathrm{p} \leq 0.05), 26.51 \% \quad(\mathrm{p} \leq 0.05)$ and $10.61 \%$ $(\mathrm{p} \leq 0.05)$, respectively. At the same time, the treatment of thermal injuries with "Acerbin" contributed to the growth of the thrombocytes population, which contained on the 10th day of treatment more thrombocytes than that on the 3rd and 5th days of the experiment by $27.54 \%(\mathrm{p} \leq 0.05)$ and $19.87 \%(\mathrm{p} \leq 0.05)$. But it was less than it was initially before therapy by $20.38 \%$ ( $\leq \leq 0.05)$. The level of hemoglobin was higher on the 10th day of treatment than on the 5th and 3rd day of therapy by $19.68 \%(\mathrm{p} \leq 0.05)$ and $9.48 \%(\mathrm{p} \leq 0.05)$, but lower than it was before therapy by $39.37 \%$ ( $\mathrm{p} \leq 0.05)$, respectively. 


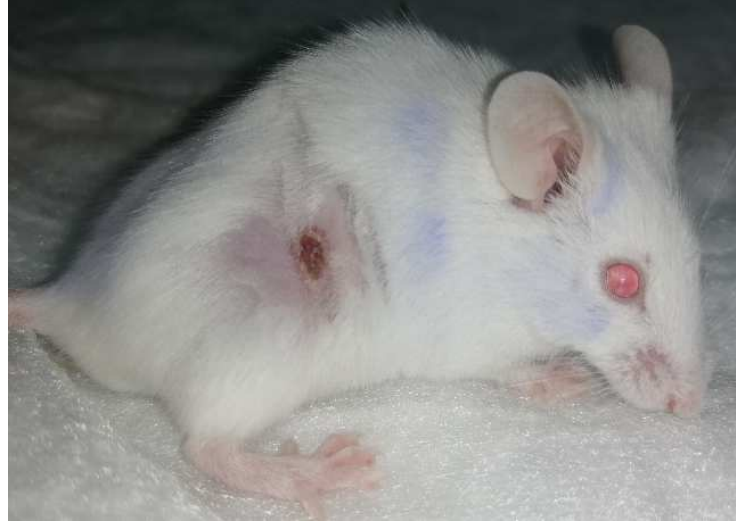

Fig. 7. Burn on the 10th day of the treatment with the "Acerbin" spray.

At the end of experiment, on the $14^{\text {th }}$ day, the thermally burnt area was $2.14 \pm 0.03 \mathrm{~mm}^{2}(\mathrm{p} \leq 0.05)$ that is smaller by $4.41 \pm 0.25$ or $60.37 \%(\mathrm{p} \leq 0.05)$ than that on the 10th day of planimetric measurements. The hemodynamics of the burn injured animals showed the increase in the erythrocytes and thrombocytes level by $81.77 \%(\mathrm{p} \leq 0.05)$ and $26.77 \%(\mathrm{p} \leq 0.05)$ to the values of $8.38 \pm 0.25 \mathrm{G} / \mathrm{mcl}$ and $480.20 \pm 25.84 \mathrm{~T} / \mathrm{mcl}(\mathrm{p} \leq 0.05)$. The concentration of hemoglobin increased by $26.79 \%$ $(\mathrm{p} \leq 0.05)$ to the index of $150.20 \pm 6.34 \mathrm{~g} / \mathrm{l}(\mathrm{p} \leq 0.05)$ relative to the results of hematological research performed on the 10th day of the experiment. The total leukocytosis on the 14th day of the experiment additionally decreased by $4.11 \%(\mathrm{p} \leq 0.05)$, in comparison with the results of the calculation on the 10th day of treatment, compared to the number of $4.20 \pm 0.16 \mathrm{~T} / \mathrm{mcl}(\mathrm{p} \leq 0.05)$. At the end of the therapy period it was determined that the quantitative content of erythrocytes was higher by $71.37 \% \quad(p \leq 0.05)$ than that on the 7 th day, by $55.47 \%(\mathrm{p} \leq 0.05)$ than that on the 5 th day, by $37.83 \%(\mathrm{p} \leq 0.05)$ than that on the $3 \mathrm{rd}$ day, but less than it was before therapy by $6.16 \%(\mathrm{p} \leq 0.05)$. The level of hemoglobin on the 14th day of the experiment increased by $59.78 \%(\mathrm{p} \leq 0.05)$, relative to the results of accounting on the 7 th day, by $94.56 \%$, relative to the results of accounting on the 5th day, by $77.96 \%$ $(\mathrm{p} \leq 0.05)$, relative to the results of accounting on the $3 \mathrm{rd}$ day. But it was lower by $1.44 \%(\mathrm{p} \leq 0.05)$ in comparison with the similar pre-therapeutic level. On the 14th day, the quantitative content of thrombocytes in the vascular bed was higher by $0.92 \%(\mathrm{p} \leq 0.05)$ than it was before treatment; by $61.68 \% \quad(\mathrm{p} \leq 0.05), 51.96 \% \quad(\mathrm{p} \leq 0.05)$, and $43.51 \%(\mathrm{p} \leq 0.05)$ than it was on the $3 \mathrm{rd}, 5 \mathrm{th}$, and 7 th days, respectively. The number of various types of leucocytes during the treatment with the vulnerary spray "Acerbin" was significantly lower than that in the previous accounting periods. Namely, it increased by $12.86 \%$ $(\mathrm{p} \leq 0.05)$ than it was before treatment, by $43.09 \%(\mathrm{p} \leq 0.05)$ than that on the 3rd day of therapy, by $29.52 \%(\mathrm{p} \leq 0.05)$, than that on the 5 th day, by $14.28 \%(\mathrm{p} \leq 0.05)$ than that on the 7 th day.

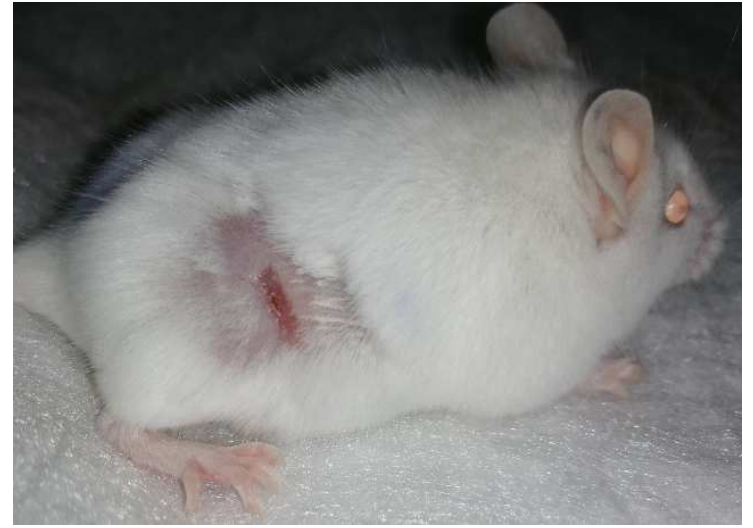

Fig. 8. Burn on the 14th day of the treatment with the "Acerbin" spray.

\section{Conclusion}

The research showed that the usage of the vulnerary spray "Acerbin" in the treatment of thermal injuries of animals has a positive influence on the dynamics of reducing the burns area. It decreased by $26.24 \%(\mathrm{p} \leq 0.05)$ on the 3rd day, by $43.91 \%(\mathrm{p} \leq 0.05)-$ on the 5 th day, by $39.43 \%(\mathrm{p} \leq 0.05)$ - on the 7 th day, by $49.05 \%(\mathrm{p} \leq 0.05)-$ on the 10th day and by $67.37 \%(\mathrm{p} \leq 0.05)$ - on the 14 th day. A positive therapeutic effect of the usage of the vulnerary spray "Acerbin" was noticed in the hemodynamics of burn-injured patients. It is consisted in a consistent increase of the number of thrombocytes by $6.40 \%(\mathrm{p} \leq 0.05)$ from the 3rd day of treatment by the 5 th one; by $5.08 \% \quad(\mathrm{p} \leq 0.05)$ - from the 5 th day by the 7 th day; by $13.21 \%(\mathrm{p} \leq 0.05)$ - from the 7 th day by the 10 th day; by $26.77 \%(\mathrm{p} \leq 0.05)$ - from the 10 th day by the 14 th day. And leucocytes decreased by $19.24 \% \quad(p \leq 0.05)$, $17.78 \%(\mathrm{p} \leq 0.05), 10.61 \%(\mathrm{p} \leq 0.05)$ and $14.11 \%(\mathrm{p} \leq 0.05)$, respectively. In addition, $\mathrm{cHb}$ increased by $59.78 \%$ $(p \leq 0.05)$ by the 14 th day of the experiment, relative to the results of the 7 th day; by $94.56 \%(\mathrm{p} \leq 0.05)$ - relative to the results of the 5 th day; by $77.96 \%(\mathrm{p} \leq 0.05)$ - relative to the results of the 3rd day. Thus, the results of monitoring of burn injured animals hemodynamics showed that the treatment with the drug "Acerbin" effectively stimulated thrombopoiesis. This positively affected the formation of primary tension and granulations, reduced total leukocytosis, which prevented the occurrence of local inflammatory complications.

\section{References}

1. E. Y. Zakirova et al., BioNanoScience. 1, 235, (2021)

2. A.Feki et al. International journal of biological macromolecules, 144, (2020)

3. N. Salhi et al., South African journal of botany, 121, 132, (2019)

4. D. W. Kim, Y. Y. Jo, U. Garagiola, J. Y. Choi, Y. J. Kang, J. H. Oh, \& S. G. Kim, International journal of molecular sciences, 10, 3473 (2020) 
5. A. P. B. S., Campelo, M. W. S., Campelo, G. A.

D. C., Britto, A. P., Ayala, S. B., Guimarães, \& P.

R. L. D., Acta Cirurgica Brasileira, 26, 38-42 (2011) 